\title{
Research Paper: The Relationship Between Covid- related Psychological Distress and Perceived Stress With Emotional Eating in Iranian Adolescents: The Mediating Role of Emotion Dysregulation
}

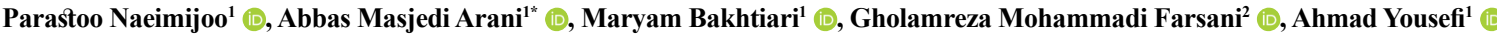

1. Department of Clinical Psychology, School of Medicine, Shahid Beheshti University of Medical Sciences, Tehran, Iran.

2. Department of Clinical Nutrition, School of Nutrition and Dietetics, Tehran University of Medical Sciences, Tehran, Iran.

\begin{tabular}{l|l}
$\begin{array}{c}\text { Use yur devic to scan } \\
\text { and read the article online }\end{array}$ \\
tween Covid-related Psychological Distress and Perceived Stress With Emotional Eating in Iranian Adolescents: The Mediating Role of \\
Emotion Dysregulation. Journal of Practice in Clinical Psychology, 9(4), 329-338. https://doi.org/10.32598/jpcp.9.4.803.1 \\
dofinttps://doi.org/10.32598/jpcp.9.4.803.1
\end{tabular}

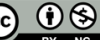

Article info:

Received: 10 Apr 2021

Accepted: 08 Aug 2021

Available Online: 01 Oct 2021

Keywords:

Perceived stress, Psychological distress, Emotional eating,

Emotion regulation,

Adolescents

\section{A B S T RACT}

Objective: The unprecedented nature of the COVID-19 pandemic and cessation of full faceto-face affiliation along with homebound restrictions have caused a variety of psychological distress among adolescents. Adolescents vary in the way they perceive such stressors and some respond with eating disturbances, which could reflect their dysfunctional emotion regulation strategies. The present research aimed at elucidating potential mediating pathways from perceived stress and psychological distress to emotional eating.

Methods: This cross-sectional study was composed of 292 adolescents who were assessed using the Perceived Stress Scale, COVID-19-Related Psychological Stress Scale, Emotional Eating subscale of the Dutch Eating Behavior Questionnaire, and Difficulties in Emotion Regulation Scale. Correlation analyses were performed to assess the relationship between variables. ANOVA was conducted to detect differences between males and females for emotional eating. Then, a mediation analysis was conducted to assess whether emotional dysregulation was a mediator between psychological distress and emotional eating.

Results: Results of path analyses indicated that a model with perceived stress and psychological distress predicting emotion eating through the mediation of emotion dysregulation was the best fit for the data $\left(\mathrm{CFI}=0.970, \mathrm{GFI}=0.949, \mathrm{df}=26, \chi^{2}=53.69, \chi^{2} / \mathrm{df}=2.06, \mathrm{P}>0.05\right.$, and $\mathrm{RMSEA}=0.069$ ). Mediation analyses showed the mediating role of emotion dysregulation in the link between perceived stress and emotional eating (Sobel's $\mathrm{z}=2.83, \mathrm{P}<0.05$ ) while, it could not function as a mediator between psychological distress and emotional eating (Sobel's $z=0.90, \mathrm{P}>0.05$ ).

Conclusion: This study contributes to our understanding of the role of emotion regulation in the relationship between perceived stress and psychological distress and emotional eating in adolescents during the COVID-19 pandemic. The implication of this study is for therapeutic intervention to target emotional dysregulation of adolescents confronted with COVID-19 stressors.

* Corresponding Author:

Abbas Masjedi Arani, PhD.

Address: Department of Clinical Psychology, School of Medicine, Shahid Beheshti University of Medical Sciences, Tehran, Iran

Tel: +98 (21) 23031548

E-mail:dr.masjediarani@gmail.com 


\section{Highlights}

- COVID-19 has imposed many psychological problems in adolescent group;

- Many adolescents perceive high stress related to COVID-19 sequeal;

- Some adolescents who perceive higher stress respond with emotional eating;

- Emotional eating related to COVID-19 perceived stress is higher in those lacking adaptive emotion regulation strategies.

\section{Plain Language Summary}

The emergence of COVID-19 created a lot of stress on teens. There are differences between adolescents in the extent to which they perceive stress. Some experience more intense stress, while others experience less stress. Unfortunately, some teens resort to eating to relieve their emotional pain, such as stress, but this eating is more common among those teens who have difficulty adjusting their emotions. That's why the issue of the ability to adjust emotion adaptively has become important topic in the COVID-19 era.

\section{Introduction}

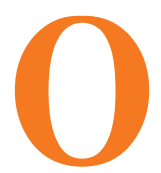

n March 11, 2020, the universe was faced with the declaration of the outbreak of novel coronavirus disease (COVID-19) (World Health Organization, 2020). Now people are experiencing a great range of threatening stressors loaded on their health, safety, and economic well-being (Brown, Doom, Lechuga-Peña, Watamura, \& Koppels, 2020). Ample evidence exists linking this pandemic with increased stress and anxiety problems (Duan \& Zhu, 2020; Fofana, Latif, Sarfraz, Bashir, \& Komal, 2020; Husky, Kovess-Masfety, \& Swendsen, 2020; Islam, Bodrud-Doza, Khan, Haque, \& Mamun, 2020; Yildırım \& Solmaz, 2020). For example, results from a meta-analysis of 3,405 studies during the COVID-19 epidemic showed that almost $24 \%$ of the participants experienced Psychological Distress (PD) (Cooke, Eirich, Racine, \& Madigan, 2020), while a similar survey on the Iranian population reported that $60 \%$ of the participants experienced anxiety and stress (Salari et al., 2020).

Life changes caused by the COVID-19 were unsettling for all age groups (Commodari \& La Rosa, 2020). However, Some groups may be more vulnerable to the psychological effects of pandemics, the effects of stress and mental destabilization may be more prominent for adolescents (Findlay \& Arim, 2020) who are experiencing a developmental stage, in which a strong enthusiasm is toward expanding social affiliation and all aspirations are directed toward cultivating a positive future full of opportunities (Smirni, Smirni, Di Martino, Operto, \& Carotenuto, 2019). However, the sudden, destabilizing COV-
ID-19 can ruin their sociability, friendship, any immediate dreams, or future planning (Golberstein, Wen, \& Miller, 2020) and exacerbate existing mental health. Now, the newly-established fragile teen's desire for autonomy, peer relationships, and regular physical activity is hindered by inevitable social distancing policies and obligatory stayat-home guidelines. Many also struggle with academic problems due to school disclosure altogether putting the teen at a higher level of stress (Golberstein et al., 2020).

While stress is defined as person adaptation in response to external and internal threats (Lecic-Tosevski, Vukovic, \& Stepanovic, 2011), Perceived Stress (PS) outlines an individual's global subjective appraisal of the threatening or non-threatening nature of an objective stress-eliciting experience as well as evaluations of own efficacy in coping (Cohen, Kamarck, \& Mermelstein, 1983). Based on what was mentioned earlier, these stressor appraisals can cause a sequence of emotional distress reactions when the person feels that $\mathrm{s} /$ he has no control or adequate resources to deal with the challenge (Lazarus \& Folkman, 1984).

The extent to which a situation is appraised stressful (i.e., PS) can generate adaptive or maladaptive outcomes (Lazarus \& Folkman, 1984). Studies on human adaptive and non-adaptive reactions to perceived and real stress have focused on many factors, like coping strategies (Yan, Gan, Ding, Wu, \& Duan, 2021), cognitive appraisals (Xu et al., 2020), and optimistic attitudes (Genç \& Arslan, 2021). One of the non-adaptive responses to PS, which has gained attention in recent studies is changes in eating patterns (Bruch, 1974; Taut, Renner, \& Baban, 2012). 
Moreover, another key factor influencing eating behaviors during the pandemic is PD, including depression, anxiety, etc. For example, a recent survey in Italy explored modified dietary habits during quarantine, with $42 \%$ attributing heightened eating to higher anxiety levels (Scarmozzino \& Visioli, 2020).

It is well established that stress and emotional state can cause loss of appetite (Macht, 2008; Yau \& Potenza, 2013), whereas for many, undesirable emotions and stress provoke a tendency to overeat - a type of eating known as Emotional Eating (EE) (Van Strien, 2018). It is also well acknowledged that during the outbreak, the prevalence of EE remarkably has increased (Kuijer \& Boyce, 2012). In recent studies aimed at exploring changes in eating habits during the lockdown, individuals from different countries reported problematic eating behaviors, including EE in response to pandemic stressors and their psychological distresses (Bemanian et al., 2021; Papandreou, Arija, Aretouli, Tsilidis, \& Bulló, 2020; Usubini et al., 2021).

These scenarios could reflect and highlight the role of Emotion Regulation (ER) in managing self-regulatory eating behaviors. ER problems have been introduced as underlying mechanisms of EE. For instance, McAtamney, Mantzios, Egan and Wallis (2021) recently reported the mediating role of emotional dysregulation between alexithymia after a period of lockdown (McAtamney, et al., 2021). ER may be relevant to stress reduction (Coulthard, Sharps, Cunliffe, \& van den Tol, 2021; Debeuf et al., 2020; Gouveia, Canavarro, \& Moreira, 2019; Sapolsky, 2007; Sim \& Zeman, 2006). In the context of COVID-19, it seems that ER strategies affect the association between PS and anxiety symptoms in isolated individuals (Xu et al., 2020). Therefore, considering the mediating role of ER between PS and EE may be a matter of question.

Overall, based on what was explained, the advent of the pandemic has inflicted many catastrophic and threatening effects on mental wellbeing. During these extraordinary times, all age groups, particularly adolescents are confronted by many stressors. Several studies have considered the adult population; however, due to developmental fragilities and immature cognitive and emotional regulation systems, adolescents are at greater risk for stress and negative psychological outcomes (Zhou, 2020). Alike adults, whose response to stress is heterogeneous (Krishnan \& Nestler, 2008), the adolescents' responses may vary based on subjective perception; hence, different responses may be produced by different individuals. A growing body of studies has shown that many adults cope with the perceived stressors by urges to eat as a means of attenuating difficult emotions during the pandemic. Nevertheless, to the best of our knowledge, a research void is evident regarding $\mathrm{EE}$ in this time frame among the teen group. As this eating pattern could represent a doubled health problem in the form of adverse weight gain and obesity in the post-pandemic era, this should be attended to. Thus, the aim of this study was to investigate predicting the role of PS and PD in EE. We also take a more comprehensive look at the mediating role of ER in relation to the above-mentioned constructs.

\section{Objectives}

We hypothesized that there would be a significant relationship between PD and PS and EE. In addition, we hypothesized that relationships between Ps and PD and ER would be important. Finally, we hypothesized that the relationship between PS and PD and EE would be mediated by ER.

\section{Materials and Methods}

\section{Procedure}

We conducted a cross-sectional survey. The survey was submitted to online social platforms at 10 A.M on 9th April 2021 for four weeks during the fourth peak. At the time of data collection, there were stringent mandatory restrictions all over the country. Participants were led to the link of questionnaires before the completion. All participants were adolescents. Inclusion criteria were as follows: (1) age range of between 13 and 18 years old, (2) Ability to read and write, (3) having access to the Internet, and (4) normal Body Mass Index (BMI) between 5 th percentile and 85 th percentile.

\section{Measurement}

Difficulties in Emotion Regulation Scale (DERS): This scale was developed by Gratz and Roemer (2004). This questionnaire consists of 36 items (overall six factors), including (1) lack of emotional awareness, (2) lack of emotional clarity, (3) difficulties controlling impulsive behaviors when distressed, (4) difficulties engaging in goaldirected behavior when distressed, (5) non-acceptance of negative emotional responses, and (6) limited access to effective ER strategies. The answers are graded on a fivepoint Likert scale ranging from 1 (almost never applies to me) to 5 (almost always applies to me). Scoring is done by summing the items. Previous studies have shown acceptable reliability and internal consistency ( $\mathrm{a}=0.80$ to 0.93 ) in clinical and non-clinical populations (Fox, Axelrod, Paliwal, Sleeper, \& Sinha, 2007; Gratz \& Roemer, 2004). 


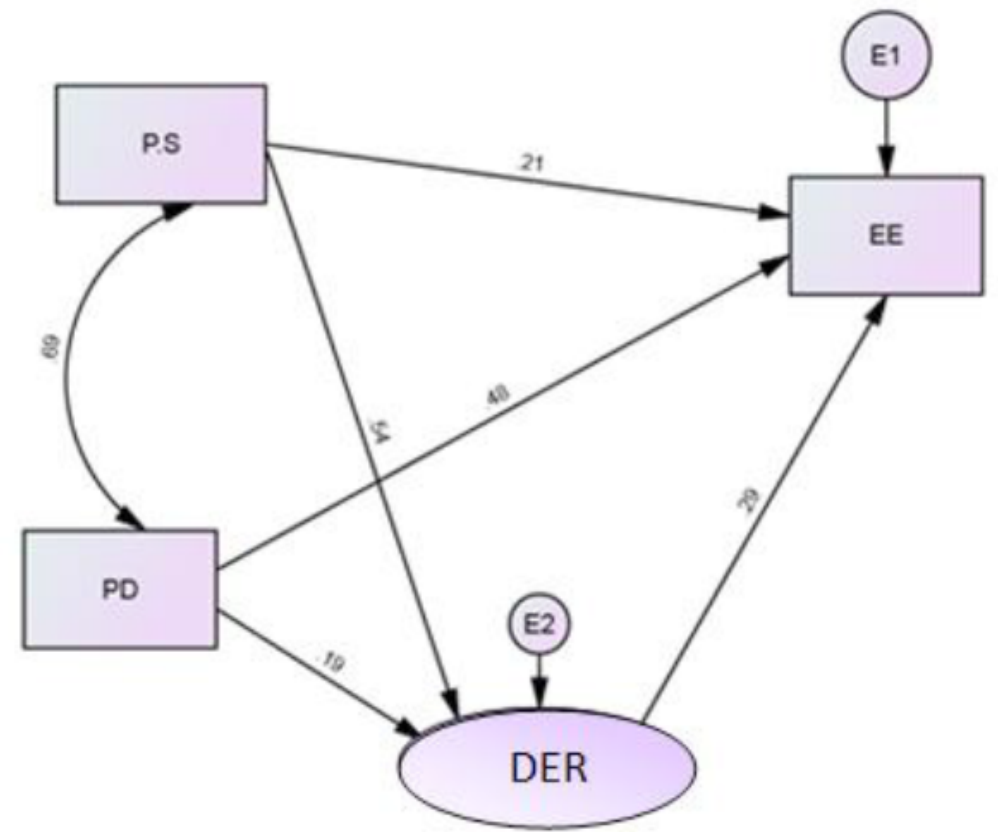

PRACTICE in CUINICAL PSYCH $\oplus$ LOGY

Figure 1. A mediation model for the relationship between perceived stress, psychological distress, and emotional eating, with emotion regulation as a mediator

PD: Psychological Distress; PS: Perceived Stress; DER: Difficulties in Emotion Regulation; EE: Emotional Eating.

The Persian version of DERS also has strong psychometric properties in both clinical (0.93) (Mazaheri, 2015) and normal (0.88) (Khanzadeh, Saeediyan, Hosseinchari, \& Edrissi, 2012) samples.

Perceived Stress Scale (PSS-14): This scale developed by Cohen et al. (1983) was used to measure the degree to which life in the past month has been experienced as uncontrollable and overwhelming. The scale has three versions (Yang \& Huang, 2003). Questions are answered on a 5-point response scale ranging from " $0=$ never" to " $4=$ very often". The scores are obtained by summing up all 14 items. Multiple studies have shown good validity and test-retest reliability (Cronbach's alpha $>0.70$ ) of PSS-14 (Lee, 2012). Reliability and internal consistency of the Persian version of the tool have been reported in the range of 0.84 to 0.93 in different studies (Khalili, Ebadi, Tavallai, \& Habibi, 2017; Maroufizadeh, Foroudifard, Navid, Ezabadi, Sobati, \& Omani-Samani, 2018; Maroufizadeh, Zareiyan, \& Sigari, 2014).

Dutch Eating Behavior Questionnaire (DEBQ): To capture participants' EE, the emotional eating subscale nested in the Dutch Eating Behavior Questionnaire (DEBQ) was used. These 13 items tapping EE are designed to assess the desire to eat in the presence of specific emotions as a means of coping. Items are rated on their frequency of occurrence on a five-point Likert scale from
" $1=$ never" to " $5=$ very often". This scale has been found to be a valid and reliable instrument for evaluating EE (e.g. Do you have a desire to eat when you are irritated?). The internal validity of the subscale using Cronbach's alpha (0.92-0.95) has been reported (Van Strien, Frijters, Bergers, \& Defares, 1986). Psychometric properties of the Persian version of DEBQ in the Iranian population showed satisfactory reliability (0.79) in the Iranian population (Nejati, Alipour, Saeidpour, \& Bodaghi, 2017).

Coronavirus Impacts Questionnaire: The psychological subscale of the Coronavirus Impacts Questionnaire Short version was used to assess PD, which is composed of two items: "I have become depressed because of the Coronavirus (COVID-19)" and "The Coronavirus (COVID-19) outbreak has impacted my psychological health negatively". The scale has shown acceptable reliability $(\mathrm{a}=0.90)$ (Conway III, Woodard, \& Zubrod, 2020).

\section{Results}

\section{Descriptive}

Demographic data included age, sex, education level, and BMI. A total of 313 participants filled out the online survey. Eight questionnaires were excluded due to incompletion or partial completion. Thirteen subjects did not meet the inclusion criteria and were excluded. 
A total of 292 participants remained, out of which $42 \%$ were males and $58 \%$ were females; the Mean $\pm \mathrm{SD}$ age was $16.11 \pm 0.99$ years old. Regarding educational level, most of the participants were in grade $10(31 \%)$, and the lowest number of participants were in grade $7(8 \%)$. The participants with BMI less than $5^{\text {th }}$ percentile and more than $85^{\text {th }}$ percentiles (CDC cut-point) we excluded for the sake of having a normal-weight sample in adolescents. The descriptive statistics of the samples are presented in Table 1. The ANOVA results showed no significant gender differences in $\mathrm{EE}(\mathrm{F}=0.107, \mathrm{df}=1, \mathrm{P}=0.744)$. There was no significant correlation between age (Pearson's $\mathrm{r}=0.007, \mathrm{P}=0.93$, 2-tailed) and BMI (Pearson's r $=0.17, \mathrm{P}=0.13$, 2-tailed) and EE. All correlation analyses are depicted in Table 2.

\section{Predictors of EE}

A path analysis was conducted using AMOS to test the hypothesis and investigate the direct and indirect effects of PS and PD on EE with a mediating role of ER (Figure 1). A P-value of 0.05 was considered statistically significant. Regarding pre-assumptions, skewness and kurtosis values indicated that all variables were normally distributed (Table 1). Variance Inflation Factor (VIF) and tolerance showed no violation of multicollinearity: $\mathrm{EE}^{*} \mathrm{PS}(\mathrm{VIF}=2.47$, tolerance $=0.40), \mathrm{EE} * \mathrm{PD}(\mathrm{VIF}=1.98$, tolerance $=0.504), \mathrm{EE}^{*} \mathrm{ER}(\mathrm{VIF}=1.83$, tolerance $=0.544)$; therefore, further analysis was allowed.

\section{Model testing and modification}

Assessment of model fit was performed using the $\chi^{2}$ goodness-of-fit test as well as the Comparative Fit Index (CFI), the Goodness of Fit Index (GFI), and the Root Mean Square Error of Approximation (RMSEA). As all indices showed good fit $(\mathrm{CFI}=0.970, \mathrm{GFI}=0.949, \mathrm{df}=26$, $\chi^{2=53.69}, \chi^{2} / \mathrm{df}=2.06, \mathrm{P}>0.05$, and $\left.\mathrm{RMSEA}=0.069\right)$, it can be concluded that the model fits the data.

The model showed that there was a direct path, that is, PS, PD, and DERS significantly explained $21 \%$, 47\%, and $29 \%$ of the variance of EE, respectively. Moreover, PS and PD accounted for $53 \%$ and $18 \%$ of the variance of DERS. Mediation model showed the indirect effect of PS (Sobel's $z=2.83, \mathrm{P}<0.05$ ) and PD (Sobel's $\mathrm{z}=0.90$, $\mathrm{P}>0.05$ ) on EE through DERS. Remarkably, PS had indirect positive effects on EE through DERS. DERS functioned as a mediator between PS and EE, which sug-

Table 1. Demographic characteristics of the samples

\begin{tabular}{|c|c|c|c|c|}
\hline \multicolumn{2}{|c|}{ Variables } & \multicolumn{3}{|c|}{ No. (\%) } \\
\hline \multirow{3}{*}{ Sex } & Male & & $122(41.78)$ & \\
\hline & Female & & $170(58.21)$ & \\
\hline & Total & & $292(100)$ & \\
\hline \multirow{6}{*}{ Educational level } & Grade 7 & & $24(8.21)$ & \\
\hline & Grade 8 & & $37(12.67)$ & \\
\hline & Grade 9 & & $49(16.78)$ & \\
\hline & Grade 10 & & $92(31.50)$ & \\
\hline & Grade 11 & & $60(20.54)$ & \\
\hline & Grade 12 & & $30(10.27)$ & \\
\hline Variables & Mean士SD & Skwedness & & Kurtosis \\
\hline Age & $16.11 \pm 0.99$ & & & \\
\hline $\mathrm{BMI}$ & $21.32 \pm 2.43$ & & & \\
\hline PD & $3.50 \pm 2.16$ & -1.08 & & 0.76 \\
\hline PS & $28.60 \pm 10.44$ & -0.33 & & -0.65 \\
\hline DER & $92.37 \pm 25.31$ & -0.75 & & 0.06 \\
\hline $\mathrm{EE}$ & $29.84 \pm 10.88$ & 0.62 & & 0.97 \\
\hline
\end{tabular}

PD: Psychological Distress; PS: Perceived Stress; DER: Difficulties in Emotion Regulation; EE: Emotional Eating; BMI: Body Mass Index. 
Table 2. The correlation matrix

\begin{tabular}{ccccc}
\hline Variables & EE & PS & PD & DER \\
\hline EE & 1 & & & \\
PS & $0.741^{* *}$ & 1 & 1 & 1 \\
\hline PD & $0.790^{* *}$ & $0.694^{* *}$ & $0.438^{* *}$ & \\
\hline DER & $0.559^{* *}$ & $0.592^{* *}$ & & PRACTICE In CLINICALCH PSC LOGY
\end{tabular}

PD: Psychological Distress; PS: Perceived Stress; DER: Difficulties in Emotion Regulation; EE: Emotional Eating; ** P<0.01.

gested that individuals with lower ability in regulating emotions experienced higher levels of EE in response to COVID-19-related stresses. However, DERS could not mediate the relationship between PD and EE (Table 3).

\section{Discussion}

The current study was conducted upon emerging research demonstrating the high prevalence of EE during the COVID-19 outbreak. We tried to look at the influence of PS and COVID-19-related PD on adolescents' $\mathrm{EE}$ in Iran. We further sought to assess whether the relation between the defined constructs is mediated by the ER strategies or not.

Overall, findings showed that the scores obtained on EE are influenced by PS and PD, and DERS. The findings of the mediation analyses indicated the indirect effects of PS on EE via DERS. The strong association between pre- dicting variables and $\mathrm{EE}$ in path analysis means the more a situation is appraised stressful by an adolescent, the more the level of EE. This corroborates previous findings suggesting higher propensities of EE in the case of PS during the outbreak (Shen, Long, Shih, \& Ludy, 2020). A positive strong correlation between PS and EE has been replicated over different phases of the pandemic among those experiencing anxiety (Di Renzo et al., 2020).

A similar trend was also obvious between PD and EE. Adolescents reported significantly greater EE urges in response to PD inflicted by COVID-19. This is in line with studies suggesting more dysfunctional eating habits and higher consumption of foods and beverages among those struggling with psychological difficulties (Freeman \& Gil, 2004; Michels et al., 2012; Talbot, Maguen, Epel, Metzler, \& Neylan, 2013), particularly during the pandemic (McAtamney et al., 2021). Therefore, our main hypothesis that emotional distress and high levels

Table 3. The direct and indirect effect of variables

\begin{tabular}{cccccc}
\hline Predictive Variables & Dependent Variables & Path Type & $\boldsymbol{\beta}$ & $\mathbf{T}$ & $\mathbf{P}$ \\
\hline PS & DER & Direct & 0.537 & 5.622 & 0.001 \\
PS & EE & Direct & 0.215 & 3.166 & 0.002 \\
PD & DER & Direct & 0.187 & 2.107 & 0.035 \\
PD & EE & Direct & 0.476 & 7.911 & 0.001 \\
DER & EE & Direct & 0.294 & 4.651 & 0.001 \\
PS & Indirect & 0.158 & Sobel Test & $<0.05$ \\
EE Via DER & & & 2.83 & Sobel Test \\
PD & Indirect & 0.055 & 0.902 & $>0.05$ \\
\hline
\end{tabular}

PD: Psychological Distress; PS: Perceived Stress; DER: Difficulties in Emotion Regulation; EE: Emotional Eating. 
of PS during lockdown are accompanied by increased self-reported EE in adolescents was confirmed.

There are several explanations about why EE might increase during the pandemic. The COVID-19- related stressors are likely to be perceived as a significant egothreatening condition for many adolescents as they are encountered by external stressors, like loss of family members, mandated stay-at-home, separation from friends, exposure to bad news as well as internal stressors, including fear of death, anticipatory anxiety of beloved sickness or death, fear, anger loneliness, and hopelessness. Therefore, many teens experience internal imbalance and respond by searching for something to pacify. This may be explained by the role of comfort food, through which the individual may try to alleviate the inner stress by resorting to foods, particularly sweets to rinse the bitterness of the inner turbulence in order to achieve solace (Di Renzo et al., 2020). Food, not only plays a diminishing role in negative effects but also serves as an interesting and accessible hobby that has no limit during a time frame replete with limitations. The increased EE can be served as a replacement for COVID-19 -related difficulties to enhance mood in a restricted adolescent.

This supports escape theory along with previous findings introducing food as a means of comfort in face of anxiety-provoking states (Heatherton \& Baumeister, 1991; Wallis \& Hetherington, 2004). This is also in line with the findings of Shen et al., (2020) showing the remarkable role of food in lessening stress and improving mood during the pandemic.

In efforts to understand the mechanisms that link stress to EE, we also hypothesized that elevations in ER difficulties in face of stress would be associated with greater engagement in EE. The results showed a direct path between ER and EE. Furthermore, a direct path exists between PS with ER difficulties. The analysis also revealed that ER plays a primary role in mediating the relationship between PS and EE. The mediating role of ER implies that ER strategies are a synergistic factor in the relationship between PS and EE during COVID-19. Probably the long-term exposure to the unpredictable nature of COVID-19 and its accompanying stressors depleted adolescents' coping resources and their ability to identify, monitor, and adaptively manage emotions that are vividly diminished. An adolescent who appraises this situation is more stressed and is less adept in deploying adaptive ER strategies and using EE as a potent coping mechanism. Unfortunately, the advent of COVID-19 exerted many limitations on adolescents' lives and they could no longer resort to typical emotion boosting strate- gies, like sports, teamwork, socializing with friends, and parties, and the only pleasurable available activity to engage was eating to modify the magnitude of stress.

Consistent with this, other studies have reported that restricted access to emotionally flexible and useful strategies in the face of negative emotions contribute to lossof-control eating (Kenardy, Arnow, \& Agras, 1996) and disordered eating (Lavender \& Anderson, 2010). The crucial role of ER in the relation between stresses and $\mathrm{EE}$ is also reported in the psychosomatic theory positing that poor emotional awareness leads to the inability to recognize hunger and results in eating in face of emotional arousal (Bruch, 1973).

Moreover, contrary to our hypothesis, the relationship between PD and EE does not seem to be mediated via ER. This could be due to the nature of our scale, which is composed of only two questions measuring holistic psychological distress. Also, as far as PS is regarded, internal symptoms and personal appraisals are engaged. Stress is construed as a symptom. ER strategies function in response to internally appraised matters while PD is a phenomenon incorporating many signs and symptoms. Thus, other factors would contribute to this association and PD may relate to EE via other paths. Overall, the results of our study indicated that training on adaptive ER is especially important for adolescents who are emotional eaters.

\section{Conclusion}

This study contributes to our understanding of the role of ER in the relationship between PS and PD and EE in adolescents during the COVID-19 pandemic. The implications of this study are for designing therapeutic interventions to target emotional dysregulation of adolescents confronted with COVID-19 stressors.

\section{Limitation and future directions}

Although the current study provides valuable insights into the psychological correlates of preventative behaviors in teens, some limitations will need to be addressed in future research. First, the cross-sectional nature of the study limits casual inferences, which highlights the need to run longitudinal research. Second, the study relied on self-report measures, leading to bias. Future research may gain the advantage of applying observational instruments. Third, the survey questionnaires were distributed solely through digital means, which excluded adolescents deprived of access to the Internet. Fourth, the sample only consisted of adolescents with normal BMI, while the study may bear different results in obese 
or underweight sample groups. This could be considered in future research.

\section{Ethical Considerations}

\section{Compliance with ethical guidelines}

This study was approved by the Research Ethics Committee of Shahid Beheshti University of Medical Sciences (Code: IR.SBMU.MSP.REC.1399.488). All ethical principles are considered in this article. The participants were informed about the purpose of the research and its implementation stages. They were also assured about the confidentiality of their information. They were free to leave the study whenever they wished, and if desired, the research results would be available to them.

\section{Funding}

The study is extracted from a $\mathrm{PhD}$. dissertation of the first author at Department of Clinical Psychology, School of Medicine, Shahid Beheshti University of Medical Sciences. All ethical principles are considered in this article. The participants were informed about the purpose of the research and its implementation stages. They were also assured about the confidentiality of their information. They were free to leave the study whenever they wished, and if desired, the research results would be available to them.

\section{Authors' contributions}

All authors equally contributed to preparing this article.

\section{Conflict of interest}

The authors declared no conflict of interest.

\section{References}

Bemanian, M., Mæland, S., Blomhoff, R., Rabben, A. K., Arnesen, E. K., Skogen, J. C., et al. (2021). Emotional eating in relation to worries and psychological distress amid the COVID-19 pandemic: A population-based survey on adults in Norway. International Journal of Environmental Research and Public Health 18(1), 130. [DOI:10.3390/ijerph18010130] [PMID] [PMCID]

Brown, S. M., Doom, J. R., Lechuga-Peña, S., Watamura, S. E., \& Koppels, T. (2020). Stress and parenting during the global COVID-19 pandemic. Child Abuse E Neglect, 110(Pt 2), 104699. [DOI:10.1016/j.chiabu.2020.104699] [PMID] [PMCID]

Bruch, H. (1973). Eating disorder: Obesity, anorexia nervesia and the person within. New York: Basic Book. https://www.google. com/books/edition/Eating_Disorders/=en
Bruch, H. (1974). Eating disorders. Obesity, anorexia nervosa, and the person within. Milton Park: Routledge \& Kegan Paul. https:/ / www.google.com/books/edition/_/Du09AAAAI

Cohen, S., Kamarck, T., \& Mermelstein, R. (1983). A global measure of perceived stress. Journal of Health and Social Behavior, 24(4), 385-96. [DOI:10.2307/2136404] [PMID]

Commodari, E., \& La Rosa, V. L. (2020). Adolescents in quarantine during COVID-19 pandemic in Italy: Perceived health risk, beliefs, psychological experiences and expectations for the future. Frontiers in Psychology, 11, 2480. [DOI:10.3389/fpsyg.2020.559951] [PMID] [PMCID]

Conway III, L. G., Woodard, S. R., \& Zubrod, A. (2020). Social psychological measurements of COVID-19: Coronavirus perceived threat, government response, impacts, and experiences questionnaires. [DOI:10.31234/osf.io/z2x9a]

Cooke, J. E., Eirich, R., Racine, N., \& Madigan, S. (2020). Prevalence of posttraumatic and general psychological stress during COVID-19: A rapid review and meta-analysis. Psychiatry Research, 292, 113347. [DOI:10.1016/j.psychres.2020.113347] [PMID] [PMCID]

Coulthard, H., Sharps, M., Cunliffe, L., \& van den Tol, A. (2021) Eating in the lockdown during the Covid 19 pandemic: Selfreported changes in eating behaviour, and associations with BMI, eating style, coping and health anxiety. Appetite, 161, 105082. [DOI:10.1016/j.appet.2020.105082] [PMID] [PMCID]

Debeuf, T., Verbeken, S., Boelens, E., Volkaert, B., Van Malderen, E., \& Michels, N., et al. (2020). Emotion regulation training in the treatment of obesity in young adolescents: Protocol for a randomized controlled trial. Trials, 21(1), 1-17. [DOI:10.1186/ s13063-019-4020-1] [PMID] [PMCID]

Di Renzo, L., Gualtieri, P., Cinelli, G., Bigioni, G., Soldati, L., Attinà, A., et al. (2020). Psychological aspects and eating habits during COVID-19 home confinement: Results of EHLC-COVID-19 Italian online survey. Nutrients, 12(7), 2152 [DOI:10.3390/nu12072152] [PMID] [PMCID]

Duan, L., \& Zhu, G. (2020). Psychological interventions for people affected by the COVID-19 epidemic. The Lancet Psychiatry, 7(4), 300-2. [DOI:10.1016/S2215-0366(20)30073-0]

Findlay, L., \& Arim, R. (2020). Canadians report lower self-perceived mental health during the COVID-19 pandemic. Retrieved from https://www150.statcan.gc.ca/n1/pub/45-28-0001/2020001/ article/00003-eng.htm

Fofana, N. K., Latif, F., Sarfraz, S., Bilal, Bashir, M. F., \& Komal B. (2020). Fear and agony of the pandemic leading to stress and mental illness: An emerging crisis in the novel coronavirus (COVID-19) outbreak. Psychiatry Research, 291, 113230. [DOI:10.1016/j.psychres.2020.113230] [PMID] [PMCID]

Fox, H., Axelrod, S., Paliwal, P., Sleeper, J., \& Sinha, R. (2007). Difficulties in emotion regulation and impulse control during cocaine abstinence. Drug and Alcohol Dependence, 89(2-3), 298301. [DOI:10.1016/j.drugalcdep.2006.12.026] [PMID]

Freeman, L. M. Y., \& Gil, K. M. (2004). Daily stress, coping, and dietary restraint in binge eating. International Journal of Eating Disorders, 36(2), 204-12. [DOI:10.1002/eat.20012] [PMID]

Genç, E., \& Arslan, G. (2021). Optimism and dispositional hope to promote college students' subjective well-being in the context of the COVID-19 pandemic. Journal of Positive School Psychology, 5(2), 87-96. [DOI:10.47602/jpsp.v5i2.255] 
Golberstein, E., Wen, H., \& Miller, B. F. (2020). Coronavirus disease 2019 (COVID-19) and mental health for children and adolescents. JAMA Pediatrics, 174(9), 819-20. [DOI:10.1001/ jamapediatrics.2020.1456] [PMID]

Gouveia, M., Canavarro, M., \& Moreira, H. (2019). Associations between mindfulness, self-compassion, difficulties in emotion regulation, and emotional eating among adolescents with overweight/obesity. Journal of Child and Family Studies, 28(1), 273-85. [DOI:10.1007/s10826-018-1239-5]

Gratz, K. L., \& Roemer, L. (2004). Multidimensional assessment of emotion regulation and dysregulation: Development, factor structure, and initial validation of the difficulties in emotion regulation scale. Journal of Psychopathology and Behavioral Assessment, 26(1), 41-54. [DOI:10.1023/ B:JOBA.0000007455.08539.94]

Heatherton, T. F., \& Baumeister, R. F. (1991). Binge eating as escape from self-awareness. Psychological Bulletin, 110(1), 86-108. [DOI:10.1037/0033-2909.110.1.86] [PMID]

World Health Organization. (2020). Coronavirus disease 2019 (COVID - 19) situation report - 62. Retrieved from https:// www.who.int/docs/default-source/coronavi\%20f.

Husky, M. M., Kovess-Masfety, V., \& Swendsen, J. D. (2020). Stress and anxiety among university students in France during COVID-19 mandatory confinement. Comprehensive Psychiatry, 102, 152191. [DOI:10.1016/j.comppsych.2020.152191] [PMID] [PMCID]

Islam, S. D. U., Bodrud-Doza, M., Khan, R. M., Haque, M. A., \& Mamun, M. A. (2020). Exploring COVID-19 stress and its factors in Bangladesh: A perception-based study. Heliyon, 6(7), e04399. [DOI:10.1016/j.heliyon.2020.e04399] [PMID] [PMCID]

Kenardy, J., Arnow, B., \& Agras, W. S. (1996). The aversiveness of specific emotional states associated with binge-eating in obese subjects. Australian \& New Zealand Journal of Psychiatry, 30(6), 839-44. [DOI:10.3109/00048679609065053] [PMID]

Khalili, R., Ebadi, A., Tavallai, A., \& Habibi, M. (2017). Validity and reliability of the Cohen 10-item Perceived Stress Scale in patients with chronic headache: Persian version. Asian Journal of Psychiatry, 26, 136-40. [DOI:10.1016/j.ajp.2017.01.010] [PMID]

Khanzadeh, M., Saeediyan, M., Hosseinchari, M., \& Edrissi, F. (2012). [Factor structure and psychometric properties of difficulties in emotional regulation scale Persian)]. International Journal of Behavioral Sciences, 6(1), 87-96. http:/ / www.behavsci.ir/article_67768.html

Krishnan, V., \& Nestler, E. J. (2008). The molecular neurobiology of depression. Nature, 455(7215), 894-902. [DOI:10.1038/ nature07455] [PMID] [PMCID]

Kuijer, R. G., \& Boyce, J. A. (2012). Emotional eating and its effect on eating behaviour after a natural disaster. Appetite, 58(3), 936-9. [DOI:10.1016/j.appet.2012.02.046] [PMID]

Lavender, J. M., \& Anderson, D. A. (2010). Contribution of emotion regulation difficulties to disordered eating and body dissatisfaction in college men. International Journal of Eating Disorders, 43(4), 352-7. [DOI:10.1002/eat.20705] [PMID]

Lazarus, R. S., \& Folkman, S. (1984). Stress, appraisal, and coping. New York: Springer Publishing Company. https://www. google.com/books/edition/Stress_Appraisal_and_
Lecic-Tosevski, D., Vukovic, O., \& Stepanovic, J. (2011). Stress and personality. Psychiatriki, 22(4), 290-7. https://psycnet. apa.org/record/2012-05156-002

Lee, E. H. (2012). Review of the psychometric evidence of the perceived stress scale. Asian Nursing Research, 6(4), 121-7. [DOI:10.1016/j.anr.2012.08.004] [PMID]

Macht, M. (2008). How emotions affect eating: A five-way model. Appetite, 50(1), 1-11. [DOI:10.1016/j.appet.2007.07.002] [PMID]

Maroufizadeh, S., Foroudifard, F., Navid, B., Ezabadi, Z., Sobati, B., \& Omani-Samani, R. (2018). The Perceived Stress Scale (PSS-10) in women experiencing infertility: A reliability and validity study. Middle East Fertility Society Journal, 23(4), 456-9. [DOI:10.1016/j.mefs.2018.02.003]

Maroufizadeh, S., Zareiyan, A., \& Sigari, N. (2014). Reliability and validity of Persian version of perceived stress scale (PSS10) in adults with asthma. Archives of Iranian Medicine, 17(5), 361-5. [PMID]

Mazaheri, M. (2015). Psychometric properties of the Persian version of the difficulties in emotion regulation scale) DERS-6 \& DERS-5-revised (in an Iranian clinical sample). Iranian Journal of Psychiatry, 10(2), 115-22. [PMID] [PMCID]

McAtamney, K., Mantzios, M., Egan, H., \& Wallis, D. J. (2021). Emotional eating during COVID-19 in the United Kingdom: Exploring the roles of alexithymia and emotion dysregulation. Appetite, 161, 105120. [DOI:10.1016/j.appet.2021.105120] [PMID] [PMCID]

Michels, N., Sioen, I., Braet, C., Eiben, G., Hebestreit, A., Huybrechts, I., et al. (2012). Stress, emotional eating behaviour and dietary patterns in children. Appetite, 59(3), 762-9. [DOI:10.1016/j.appet.2012.08.010] [PMID]

Nejati, V., Alipour, F., Saeidpour, S., \& Bodaghi, E. (2017). [Psychometric properties of Persian version of Dutch Eating Behavior Questionnaire (Persian)]. Journal of Fundamentals of Mental Health, 20(1), 5-14. [DOI:10.22038/JFMH.2017.10033]

Papandreou, C., Arija, V., Aretouli, E., Tsilidis, K. K., \& Bulló, M. (2020). Comparing eating behaviours, and symptoms of depression and anxiety between Spain and Greece during the COVID-19 outbreak: Cross-sectional analysis of two different confinement strategies. European Eating Disorders Review, 28(6), 836-46. [DOI:10.1002/erv.2772] [PMID] [PMCID]

Salari, N., Hosseinian-Far, A., Jalali, R., Vaisi-Raygani, A., Rasoulpoor, S., Mohammadi, M., et al. (2020). Prevalence of stress, anxiety, depression among the general population during the COVID-19 pandemic: A systematic review and meta-analysis. Globalization and Health, 16(1), 92. [DOI:10.1186/ s12992-020-00589-w] [PMID] [PMCID]

Sapolsky, R. M. (2007). Stress, Stress-Related Disease, and Emotional Regulation. In J. J. Gross (ed.), Handbook of Emotion Regulation (pp. 606-15). New York: The Guilford Press. https:// psycnet.apa.org/record/2007-01392-030

Scarmozzino, F., \& Visioli, F. (2020). COVID-19 and the subsequent lockdown modified dietary habits of almost half the population in an Italian sample. Foods, 9(5), 675. [DOI:10.3390/ foods9050675] [PMID] [PMCID]

Shen, W., Long, L. M., Shih, C. H., \& Ludy, M. J. (2020). A humanities-based explanation for the effects of emotional eating and perceived stress on food choice motives during the 
COVID-19 pandemic. Nutrients, 12(9), 2712. [DOI:10.3390/ nu12092712] [PMID] [PMCID]

Sim, L., \& Zeman, J. (2006). The contribution of emotion regulation to body dissatisfaction and disordered eating in early adolescent girls. Journal of Youth and Adolescence, 35(2), 207-16. [DOI:10.1007/s10964-005-9003-8]

Smirni, D., Smirni, P., Di Martino, G., Operto, F. F., \& Carotenuto, M. (2019). Emotional awareness and cognitive performance in borderline intellectual functioning young adolescents. The Journal of Nervous and Mental Disease, 207(5), 365-70. [DOI:10.1097/NMD.0000000000000972] [PMID]

Talbot, L. S., Maguen, S., Epel, E. S., Metzler, T. J., \& Neylan, T. C. (2013). Posttraumatic stress disorder is associated with emotional eating. Journal of Traumatic Stress, 26(4), 521-5. [DOI:10.1002/jts.21824] [PMID]

Taut, D., Renner, B., \& Baban, A. (2012). Reappraise the situation but express your emotions: Impact of emotion regulation strategies on ad libitum food intake. Frontiers in Psychology, 3, 359. [DOI:10.3389/fpsyg.2012.00359] [PMID] [PMCID]

Usubini, A. G., Cattivelli, R., Varallo, G., Castelnuovo, G., Molinari, E., Giusti, E. M., et al. (2021). The relationship between psychological distress during the second wave lockdown of COVID-19 and emotional eating in italian young adults: The mediating role of emotional dysregulation. Journal of Personalized Medicine, 11(6), 569. [DOI:10.3390/jpm11060569] [PMID] [PMCID]

Van Strien, T. (2018). Causes of emotional eating and matched treatment of obesity. Current Diabetes Reports, 18(6), 35 [DOI:10.1007/s11892-018-1000-x] [PMID] [PMCID]

Van Strien, T., Friiters, J. E., Bergers, G. P., \& Defares, P. B. (1986). The Dutch Eating Behavior Questionnaire (DEBQ) for assessment of restrained, emotional, and external eating behavior. International Journal of Eating Disorders, 5(2), 295-315. [DOI:10.1002/1098-108X(198602)5:23.0.CO;2-T]

Wallis, D. J., \& Hetherington, M. M. (2004). Stress and eating: The effects of ego-threat and cognitive demand on food intake in restrained and emotional eaters. Appetite, 43(1), 39-46. [DOI:10.1016/j.appet.2004.02.001] [PMID]

Xu, C., Xu, Y., Xu, S., Zhang, Q., Liu, X., Shao, Y., et al. (2020) Cognitive reappraisal and the association between perceived stress and anxiety symptoms in COVID-19 isolated people. Frontiers in Psychiatry, 11, 858. [DOI:10.3389/fpsyt.2020.00858] [PMID] [PMCID]

Yan, L., Gan, Y., Ding, X., Wu, J., \& Duan, H. (2021). The relationship between perceived stress and emotional distress during the COVID-19 outbreak: Effects of boredom proneness and coping style. Journal of Anxiety Disorders, 77, 102328. [DOI:10.1016/j.janxdis.2020.102328] [PMID] [PMCID]

Yang, T., \& Huang, H. (2003). [An epidemiological study on stress among urban residents in social transition period (Chinese)]. Zhonghua liu xing bing xue za zhi=Zhonghua liuxingbingxue zazhi, 24(9), 760-4. [PMID]

Yau, Y. H. C., \& Potenza, M. N. (2013). Stress and eating behaviors. Minerva Endocrinologica, 38(3), 255-67. [PMID] [PMCID]

Yıldırım, M., \& Solmaz, F. (2020). COVID-19 burnout, COVID-19 stress and resilience: Initial psychometric properties of COVID-19 Burnout Scale. Death Studies, 1-9. [PMID]
Zhou, X. (2020). Managing psychological distress in children and adolescents following the COVID-19 epidemic: A cooperative approach. Psychological Trauma, 12(S1), S76-8. [DOI:10.1037/ tra0000754] [PMID] 